\title{
Surface Activity Interactions in Aqueous Solution of Anionic Surfactants with a Water Treatment Protein from Moringa oleifera Seeds
}

\author{
Habauka M. Kwaambwa ${ }^{1}$, Raymond Maikokera' ${ }^{2}$, Fiona M. Nermark ${ }^{3}$ \\ ${ }^{1}$ Polytechnic of Namibia, School of Health and Applied Sciences, Windhoek, Namibia \\ ${ }^{2}$ Varichem Pharmaceuticals, Harare, Zimbabwe \\ ${ }^{3}$ Botswana College of Agriculture, Gaborone, Botswana \\ Email: "hkwaambwa@polytechnic.edu.na, ${ }^{*}$ hmkwaambwa@yahoo.com, maikokerar@varipharm.co.zw, \\ fselato@gmail.com
}

Received 19 January 2015; accepted 8 February 2015; published 11 February 2015

Copyright @ 2015 by authors and Scientific Research Publishing Inc.

This work is licensed under the Creative Commons Attribution International License (CC BY).

http://creativecommons.org/licenses/by/4.0/

(c) (i) Open Access

\begin{abstract}
The interaction of anionic surfactants sodium dodecylbenzenesulphonate (SDBS) and sodium bis (2-ethyl-1-hexylsulfosuccinate) (AOT) with the water treatment protein extracted from Moringa oleifera seeds has been investigated by surface tension measurements. The results were compared with previously reported studies using surface tension and zeta potential measurements of the same protein with an anionic surfactant sodium dodecylsulphate. There is a strong electrostatic interaction between the protein and the surfactants characterized by a local maximum at intermediate surfactant concentration. This surfactant concentration depends on the protein concentration and corresponds to the surfactant concentration at the point of charge reversal (zeta potential $=0 \mathrm{mV}$ ). The number of surfactant molecules required to neutralize the positive charges on the protein was found to be 8 per protein molecule.
\end{abstract}

\section{Keywords}

Anionic, Critical Micelle Concentration, Surface Tension, Surfactant, Moringa oleifera, Zeta Potential

\section{Introduction}

It is well known that the local environment determined by parameters such as $\mathrm{pH}$, salt concentration and the

*Corresponding author.

How to cite this paper: Kwaambwa, H.M., Maikokera, R. and Nermark, F.M. (2015) Surface Activity Interactions in Aqueous Solution of Anionic Surfactants with a Water Treatment Protein from Moringa oleifera Seeds. Green and Sustainable Chemistry, 5, 31-38. http://dx.doi.org/10.4236/gsc.2015.51005 
presence of surfactant can alter significantly the behaviour of biological macromolecules. The interaction between surfactants and proteins is an active field of research in colloid science because very often in practice the proteins and surfactants are present in the same systems such as industrial, biological, pharmaceutical, and cosmetic systems. Protein-surfactant interaction is important in understanding stability and structural changes in proteins. They may lead to the formation of protein-surfactant complexes which can be soluble or insoluble in aqueous medium [1] [2]. Due to the existence of nonpolar and ionic amino acid side chains in protein molecules, the formation of these complexes is driven by electrostatic interactions between the charged head groups of the surfactant and the oppositely charged units of the protein and also by hydrophobic interactions [3]-[5]. Interaction of globular proteins, especially bovine serum albumin (BSA) with surfactants, in particular sodium dodecyl/ sulphate, SDS, has been extensively studied aiming to understand how surfactant binding affects the protein structure and function [3] [4]. Several spectroscopic and physicochemical techniques have been used to investigate the assembled protein-surfactant complexes [6] [7]. There are several studies that have widened the range of the researches of the interactions of the protein with surfactants, but not enough to understand the role of the hydrophobic and electrostatic interactions between protein and surfactant.

The physicochemical characterisation of the water treatment cationic Moringa oleifera (MO) seed protein is important in order to understand the nature of the protein and its interaction with other components particularly in water treatment. This study is an extension of the previous work of the interaction of the water treatment MO seeds protein with an anionic surfactant sodium dodecylsulphate (SDS) studied by surface tension and ultrasonic velocity measurements [8]. The anionic surfactants used in this study of using surface tension were sodium dodecylbenzenesulphonate (SDBS) and sodium bis(2-ethyl-1-hexylsulfosuccinate) (AOT) and their chemical structures are given in Figure 1. The surfactants differ in their hydrocarbon chemical chains to SDS (also shown in Figure 1 for comparison purposes).

The protein from seeds of MO shows some surface activities, i.e. it's effective in reducing surface tension of water from $72 \mathrm{mN} / \mathrm{m}$ to about $30-40 \mathrm{mN} / \mathrm{m}$ [9]. The proteins can be identified with some critical concentrations at which the surface tension begins to drop (proteins weakly surface active at low concentrations). The onset of surface activity in the concentration range studied of the MO seeds proteins compared to three common proteins, bovine serum albumin (BSA), lysozyme and frog foam protein, is of the order frog foam > BSA > MO > lysozyme.

Surface tension detected the adsorption of the protein at the air-water interface and indicated that the protein is weakly surface active at low concentrations, requiring substantially higher solution concentration to achieve maximum reduction in surface tension. The poor adsorption of the protein at low concentrations may be attributed to electrostatic repulsion among the charged adsorbed molecules due to high charge density in the protein molecule. The proteins from Moringa seeds are reported to be densely charged cationic molecules in water solution. This is in line with the literature report that proteins exhibit greater surface activity near the isoelectric point, because of minimization of electrostatic repulsion among the identically charged adsorbed molecules. In addition, a soluble protein has hydrophilic parts located on the outside of the molecule and the hydrophobic regions are buried resulting in low affinity for the air-water interface. The low surface activity of the protein agrees with high solubility in water observed for the protein.

The weak surface activity is important in water treatment because if very surface active, then one would require high concentrations before getting the protein molecules in the bulky to start the water purification process. It is, however, important to point out that surface activity isn't enough in determining whether or not the protein has water pollutant removal properties but it is merely one of its peculiar properties that play some role in water treatment.
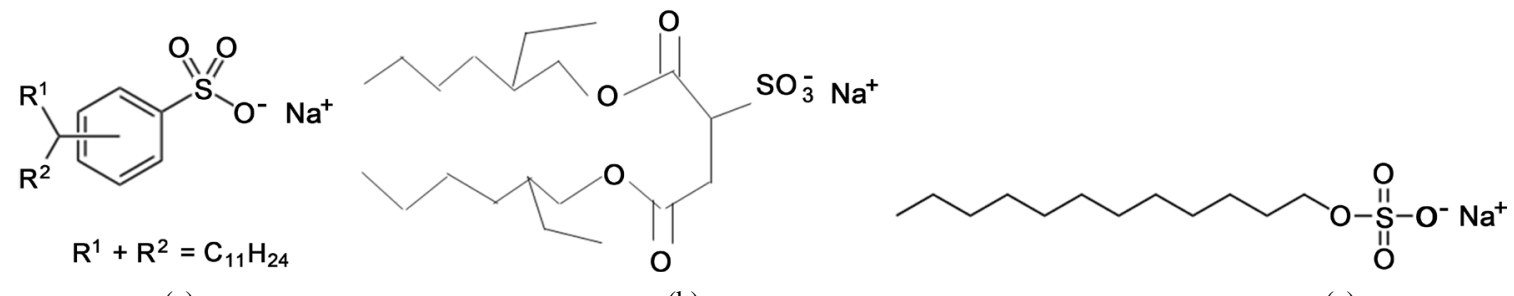

(a)

(b)

(c)

Figure 1. Chemical structures of the anionic surfactants: (a)—sodium dodecylbenzenesulphonate (SDBS); (b)—sodium bis(2-ethyl-1-hexylsulfosuccinate) (AOT); (c)—sodium dodecylsulphate (SDS). 


\section{Materials and Methods}

\subsection{Materials}

The extraction and purification of protein powder was done using the method of Ndabigengesere and Narasiah [10] [11], and the experimental details are as described previously by Kwaambwa and Maikokera [12]. The anionic surfactants used were sodium dodecylbenzenesulphonate (SDBS) and sodium bis(2-ethyl-1-hexylsulfosuccinate (AOT), and both were purchased from Sigma-Aldrich and used without further purification. Ultrapure water (UHQ, Elga, Wycombe, UK) was used to prepare the mixtures.

\subsection{Surface Tension Measurements}

Surface tension was measured with a Kruss (Hamburg, Germany) K9 digital tensiometer using the Du Nouy ring method, calibrated using ultrapure water. The platinum ring was cleaned between each reading by flaming (Bunsen burner) to remove any residual deposits. The surface tension measurements were made immediately after pouring the protein/surfactant solution in the sample trough and were done at room temperature $\left(23^{\circ} \mathrm{C} \pm\right.$ $2^{\circ} \mathrm{C}$ ). The readings were taken in triplicate for each individual solution to check reproducibility and the surface tension values were within an error less than or equal to $\pm 3 \mathrm{mN} \cdot \mathrm{m}^{-1}$.

Surfactant solutions in the presence and absence of protein were used to study the protein-surfactant interaction. The freeze-dried protein was dissolved in UHQ water. The adsorption at the air-water interface from binary solutions of protein extracted from MO seeds and surfactant was followed by surface tension measurements by keeping the protein concentration (\%w/v) constant and varying the surfactant concentration up to concentrations higher than the critical micelle concentration (CMC). The CMC values in water for most commercial surfactants are available in the literature, and the results from individual laboratories may vary slightly depending upon the method and conditions of the laboratory. The surface tension measurements were measured at room temperature immediately after sample preparation

\section{Results and Discussion}

Figure 2 shows the plots representing the variation of the surface tension, $\gamma$, with the SDBS concentration, i.e. In (surfactant concentration). This is based on the Gibbs adsorption equation isotherm [13]. Similar plots were obtained for the protein/AOT systems but are not shown here. The CMC was taken as the concentration corresponding to the break in the plots representing the variation of the surface tension, $\gamma$, with ln (surfactant concentration) for surfactant solutions without protein. The CMC values in water estimated from the surface tension plots for SDBS and AOT were $2.11 \mathrm{mM}$ and $2.48 \mathrm{mM}$, respectively. The CMC values for SDBS and AOT obtained are in good agreement with the literature values of $2.14 \mathrm{mM}$ and $2.6 \mathrm{mM}$, respectively, in water at $25^{\circ} \mathrm{C}$ as reported in Holmberg [14]. Figure 2 also shows that SDBS has the ability to reduce the surface tension of water to as low as approximately $32 \mathrm{mN} \cdot \mathrm{m}^{-1}$.

The surface tension data for the mixed solutions of SDBS with different coagulant protein concentration $(\% \mathrm{w} / \mathrm{v})$ is also shown in Figure 2. At low SDBS concentration, the surface tension of the mixed system is lower than that of pure surfactant, which indicates formation of more surface-active complexes arising from the binding of SDBS to the protein. The data exhibit an increase in surface tension at intermediate SDBS concentrations, with a local maximum occurring at $0.2 \mathrm{mM}$ and $0.768 \mathrm{mM}$ for $0.01 \%$ and $0.05 \%$, respectively. It is interesting that the maximum in surface tension profile for $0.05 \%$ protein occurs at approximately the same SDBS concentration of $0.768 \mathrm{mM}$ as the maximum observed in the solution viscosity [15].

For all protein/surfactant systems, it was observed that there was a certain anionic surfactant concentration at which precipitation was visible as shown in Figure 3 for protein/AOT system as an example. This surfactant concentration was taken to be the surfactant precipitation concentration $(p c)$ for a given protein/surfactant system and it coincides with the surfactant concentration at the surface tension maximum mentioned above. As stated earlier, the MO protein is known to be positively charged in water (isoelectric point of the protein is between 10 and 11) [16] and so it can form a precipitate with oppositely charged anionic surfactant due to the formation of neutral complexes of protein-anionic surfactant. In Table 1, the observed $p c$ values, which increase with increase in protein concentration, are given for protein/AOT system. Green et al. [17] observed similar precipitation phenomenon for SDS/lysozyme system. The complexation of the protein with AOT that leads to the formation of insoluble precipitates is ascribed to charge neutralization between the protein and surfactant ions. 


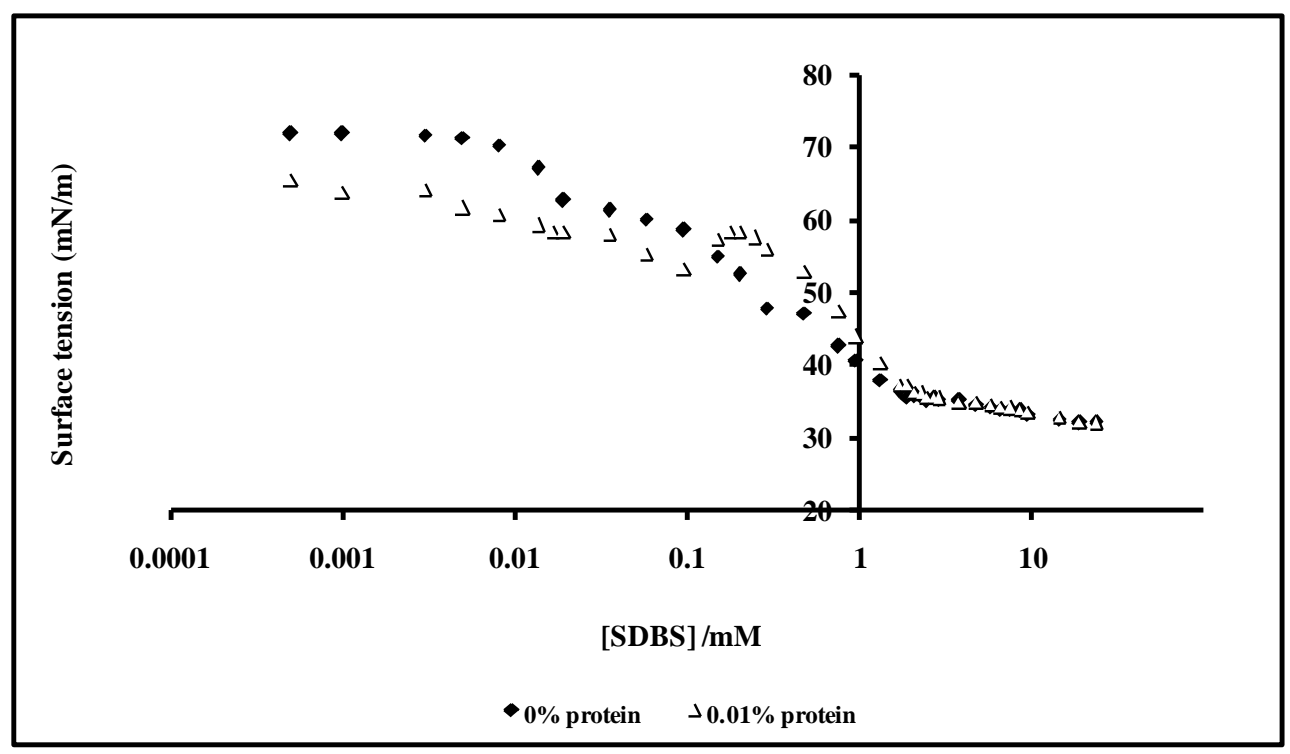

(a)

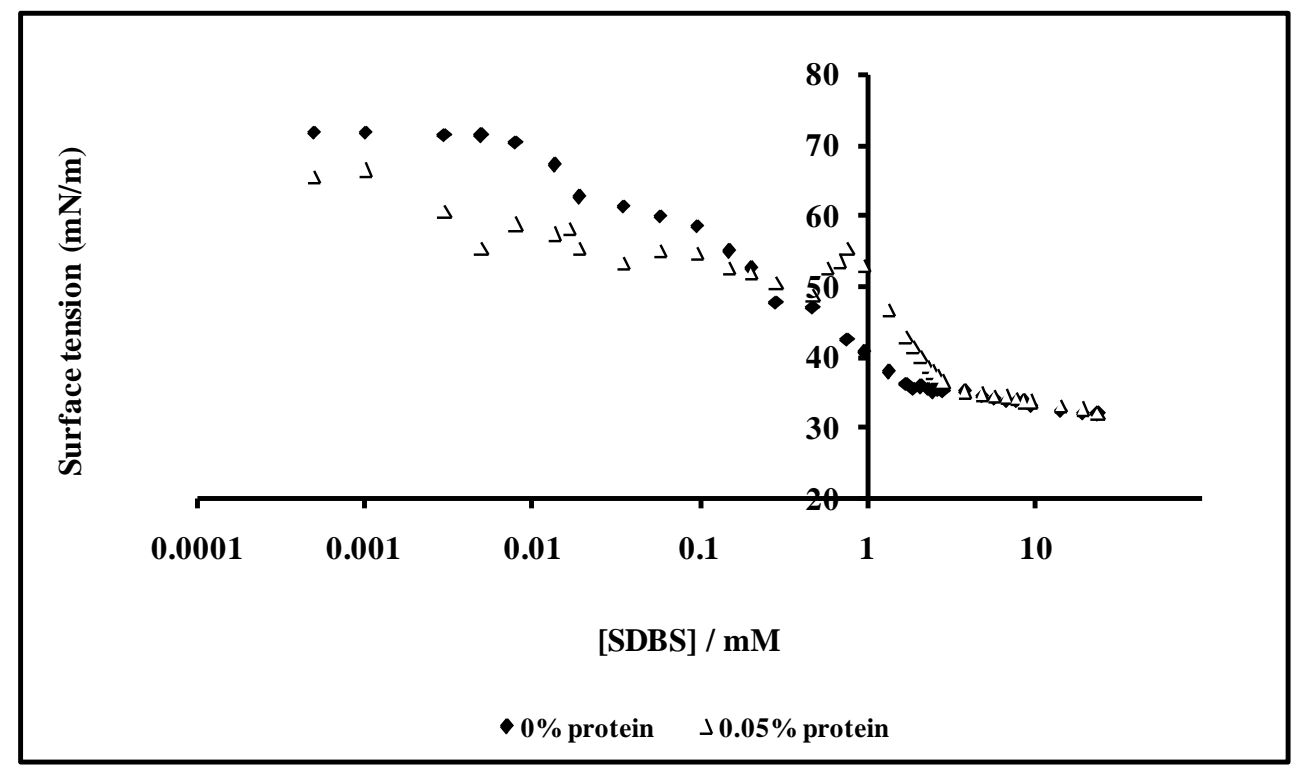

(b)

Figure 2. The effect of coagulant protein on the surface tension of SDBS in water. Panels (a) and (b) are $0.01 \%$ and $0.05 \%$ protein respectively. The protein/SDBS interaction was studied by means of the Du Nouy ring method.

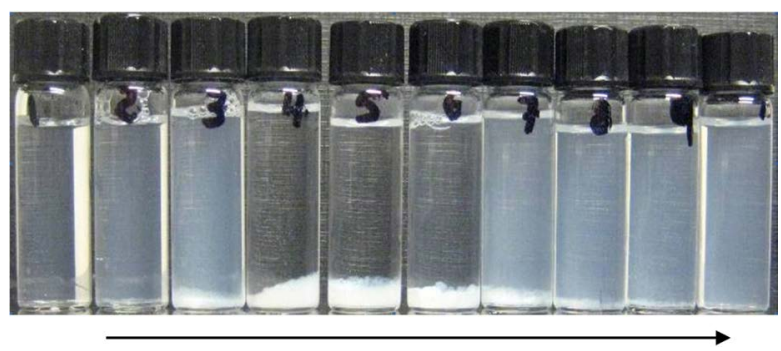

Figure 3. Typical visual effect of increasing AOT surfactant concentration on MO seeds protein solution $(0.05 \% \mathrm{w} / \mathrm{v})$. 
Table 1. Summary of the observed and calculated parameters for the coagulant protein/AOT system.

\begin{tabular}{ccc}
\hline Protein concentration $(\% \mathrm{w} / \mathrm{v})$ & Protein concentration $(\mathrm{mM})$ & $p c(\mathrm{mM})$ \\
\hline 0.01 & 0.0137 & 0.202 \\
0.02 & 0.0274 & 0.302 \\
0.03 & 0.0411 & 0.403 \\
0.05 & 0.0684 & 0.644 \\
\hline
\end{tabular}

In summary, it is here stated that the data exhibit a slight increase in surface tension at intermediate concentrations for all three anionic surfactant/protein systems, and these are the same solutions in which precipitation was observed. In other words, the $p c$ values correspond to the anionic surfactant concentrations at which the maxima in surface tensions isotherms in the intermediate surfactant concentration range occur.

The surface tension profiles systems protein/SDBS and protein/AOT show similar trends to those observed for SDS/protein system. The protein interacts strongly with anionic surfactants such as SDS, AOT and SDBS and might have specific binding sites for such surfactants. It is important to point out that any differences in the surface tension profiles can be attributed to structural differences in the anionic surfactants. For instance, the two anionic surfactants SDBS and SDS only differ in their head groups (SDBS has a sulfonate while SDS has a sulphate head group). Figure 4(a) shows a comparison of surface tension profiles for the two surfactants SDBS and SDS in the presence of $0.01 \%$ protein. The difference in local maximum positions in the surface tension profiles for the two surfactants in presence of same protein concentration ( $0.01 \%$ protein) may suggest head group effect in the interaction of the two surfactants with the protein. It can be seen that the maximum occurs at lower surfactant concentration for SDBS (maximum at $0.2 \mathrm{mM}$ ) than for SDS with a maximum at $0.768 \mathrm{mM}$.

Note that in Figure 4(b), the surface tension data is re-plotted against reduced surfactant concentration (i.e. c/ $\mathrm{CMC}$ ) so that the protein-surfactant interactions in different surfactant systems could be compared relative to CMC. In other words, re-scaling of the concentration in this manner should account for the effect of micellisation of the different types of surfactants and magnitudes of the surface tension data which reflects protein-surfactant interactions. The local maximum for the two curves now coincide suggesting that the difference in local maximum positions in Figure 4(a) may be due to micellisation of the surfactants (CMC is affected by surfactant head group). These studies provide further support of specific adsorption of surfactants to the protein. The surface tension at similar low surfactant concentrations initially decreased. When the concentration is increased beyond the point at which the interface is fully occupied, further surfactant molecules are dispersed in the bulk solution, either alone or associated with the protein.

Previously Kwaambwa and Rennie [18] studied the effect of SDS concentration on the zeta potential $(\zeta)$ of the MO protein in aqueous solution. The zeta potential was used to identify the points of charge reversal in the solutions. The concentration for neutralization increased with protein concentration. The surfactant concentration observed at the local maximum in surface tension corresponds to anionic surfactant concentration at the cross-over point of the zeta potential $(\zeta=0 \mathrm{mV})$.

Using the determined amino acid composition [19] and the Protein calculator v3.3 [20], the molecular weight of the protein was estimated to be $7.307 \mathrm{kDa}$ [19]. The \% protein from both surface tension measurements and zeta potential could then be converted to a concentration in mM. Figure 5 shows the plot of surfactant concentration (mM) versus protein concentration for the surface tension and zeta potential data. The data results in a single linear plot independent of the surfactant. The number of surfactant molecules associated with each protein molecule was found to be $\sim 8 \pm 1$ molecules per protein molecule from the slope of linear plot. The value agrees with amino acid sequencing results by Gassenschmidt et al. [21] and Broin et al. [22], who reported that the protein extracted from MO seeds has 8 negatively charged amino acid residues. The MO protein interacts with surfactants in the order anionic > cationic > zwitterionic/non-ionic [8] [18] [23].

\section{Conclusion}

The surfactants SDBS and AOT interact strongly with cationic protein extracted from MO seeds as evidenced from surface tension measurements. There is a reasonable agreement in the CMC values determined by surface 


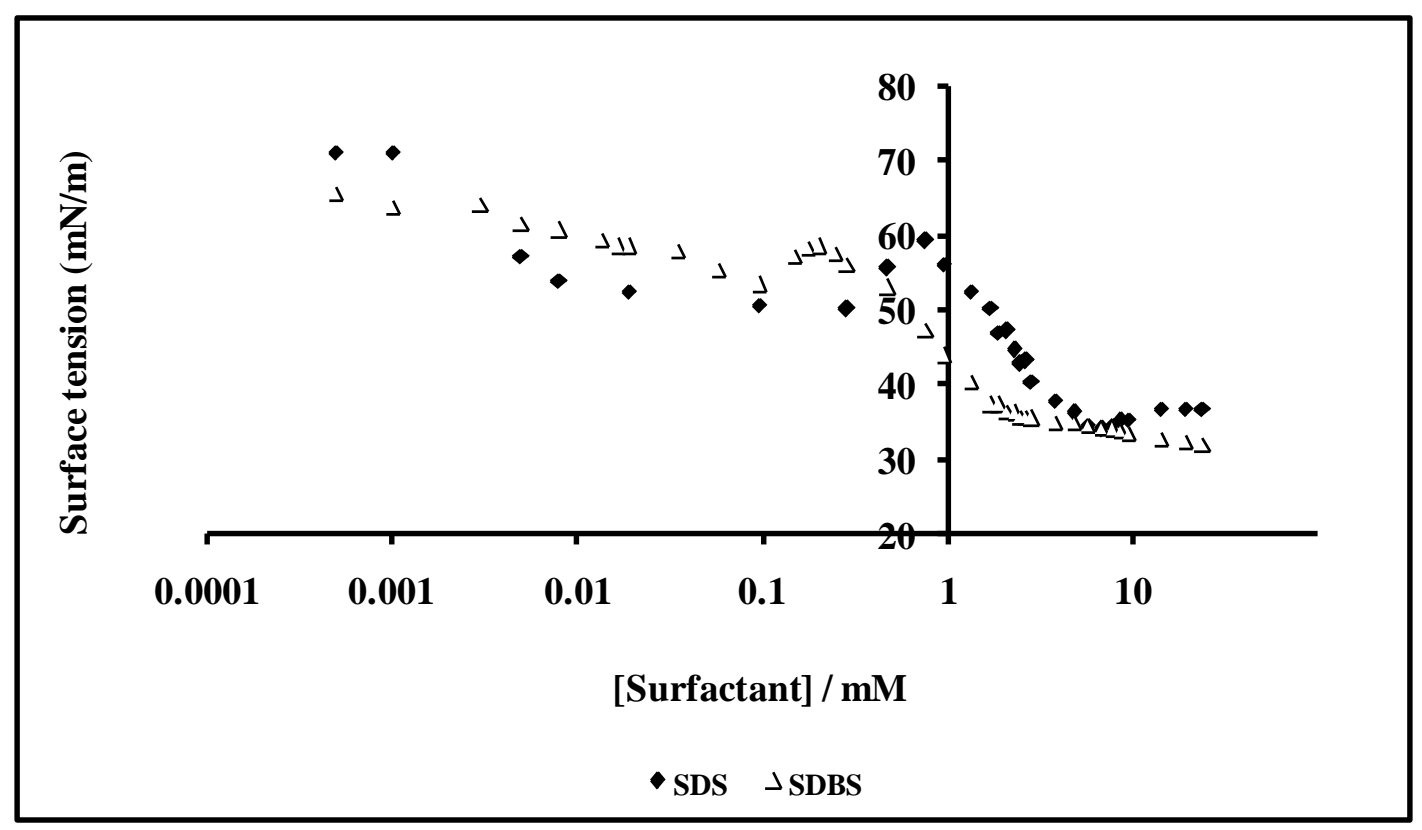

(a)

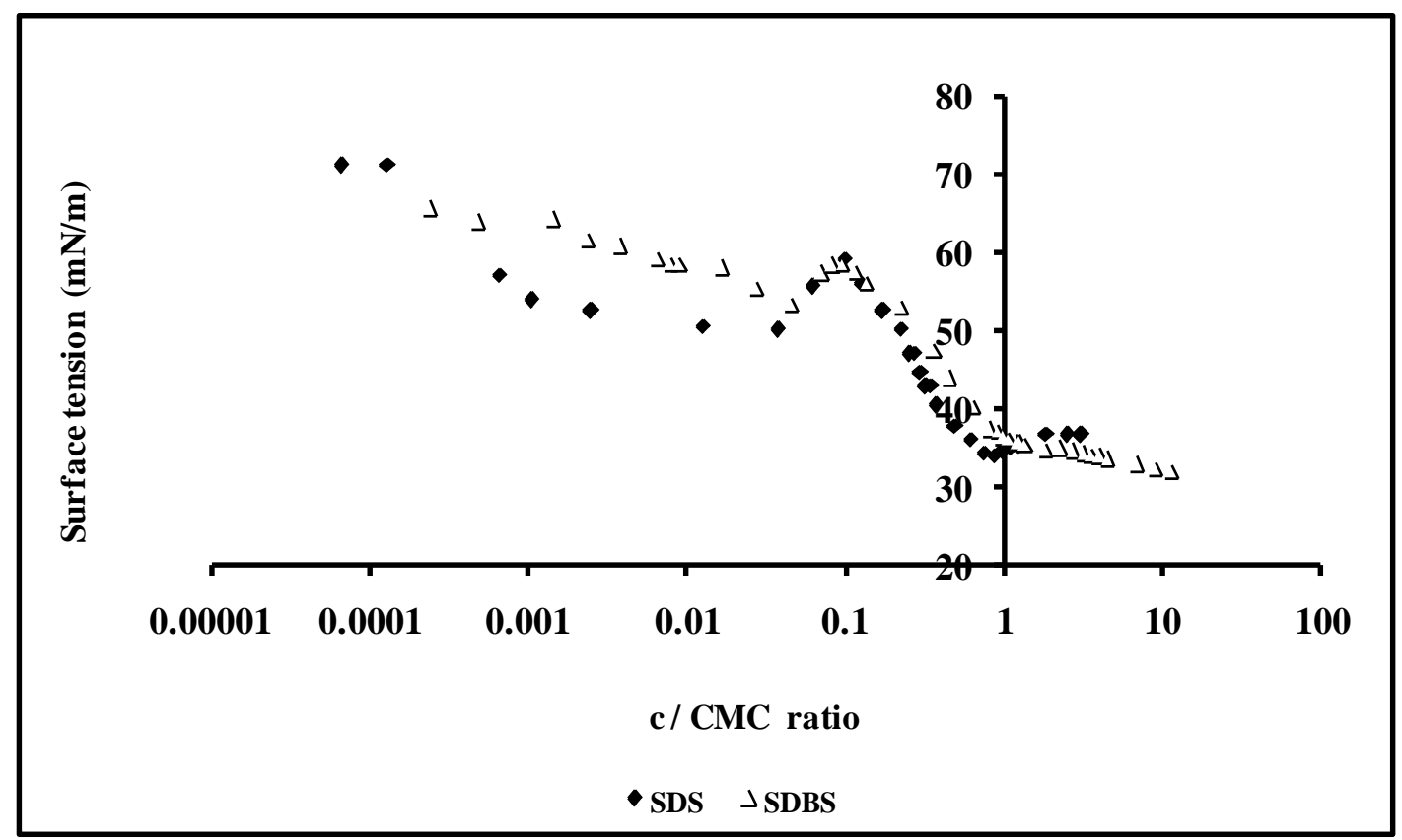

(b)

Figure 4. The effect of $0.01 \%$ coagulant protein on the surface tensions of SDS and SDBS in water. (a) Surface tension plotted versus surfactant concentration, c; (b) Surface tension plotted versus the c/CMC ratio.

tensions (2.11 $\mathrm{mM}$ and $2.48 \mathrm{mM}$ for SDBS and AOT, respectively) with the values reported in literature. The interaction behaviour of the protein with these surfactants is similar to that observed with SDS. There is an increase in the surface tension of the intermediate surfactant range which corresponds to the precipitation concentration $(p c)$ and the concentration at which zeta potential is zero (point of charge reversal of the protein from positive to negative). From the points of charge reversal and surface tension maxima, it was estimated that $8 \pm 1$ anions are required to neutralize the positive charges of each protein molecule. This clearly demonstrates that negative surfactant headgroup is responsible in the protein-surfactant concentration. 


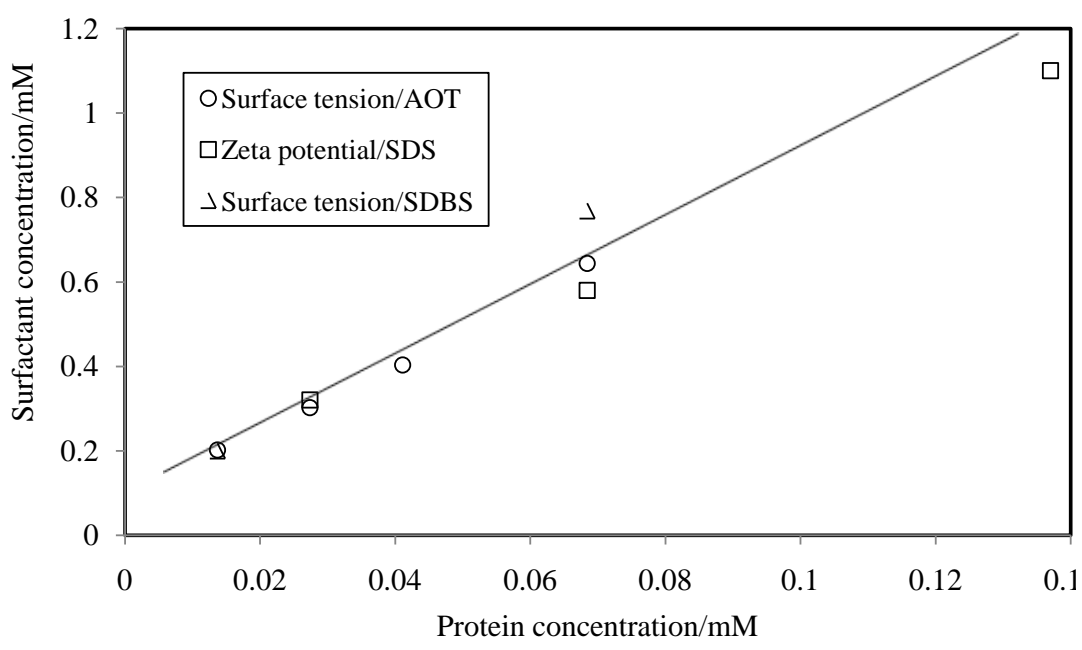

Figure 5. Surfactant concentration at $\zeta=0 \mathrm{mV}$ (cross over point) and surface tension maximum as a function of protein concentration. The linear equation fitted to these point is [Surfactant] $=8.0$ [protein $]+0.11$.

\section{Acknowledgements}

The authors are grateful to the Polytechnic of Namibia IRPC and University of Botswana ORD for supporting this study.

\section{References}

[1] Morén, K.A. and Khan, A. (1999) Phase Behaviour and Phase Structure of Protein-Surfactant-Water System. Journal of Colloid and Interface Science, 218, 397-403. http://dx.doi.org/10.1006/jcis.1999.6433

[2] Miller, R., Fainerman, V.B., Makievski, A.V., Krägel, J., Grigoriev, D.O., Kazako, V.N. and Sinyachenko, O.V. (2000) Dynamics of Protein and Mixed Protein/Surfactant Adsorption Layers at the Water/Fluid Interface. Advances in Colloid and Interface Science, 86, 39-82. http://dx.doi.org/10.1016/S0001-8686(00)00032-4

[3] Mamura, T. (2000) Surfactant Protein Interactions. In: Encyclopedia of Surface and Colloid Science, 5230-5243.

[4] González-Pèrez, A., Ruso, J.M., Prieto, G. and Sarmiento, F. (2004) Physicochemical Study of Ovalbumin in the Presence of Sodium Dodecylsulphate in Aqueous Media. Colloid and Polymer Science, 282, 351-356. http://dx.doi.org/10.1007/s00396-003-0942-x

[5] Bastrzyk, A., Polowczyk, I., Szeląg, E. and Sadowski, Z. (2008) The Effect of Protein Surfactant Interaction on Magnesite Rock Flotation. Physicochemical Problems of Mineral Processing, 42, 261-269.

[6] Jones, M.N. (1992) Surfactant Interactions with Biomembranes and Proteins. Chemical Society Reviews, 21, 127-136. http://dx.doi.org/10.1039/cs9922100127

[7] Turro, N.J. and Lei, X.-G. (1995) Spectroscopic Probe Analysis of Protein-Surfactant Interactions: The BSA/SDS System. Langmuir, 11, 2525-2533. http://dx.doi.org/10.1021/la00007a035

[8] Kwaambwa, H.M. and Nermark, F.M. (2013) Interactions in Aqueous Solution of a Zwitterionic Surfactant with a Water Treatment Protein from Moringa oleifera Seeds Studied by Surface Tension and Ultrasonic Velocity Measurements. Green and Sustainable Chemistry, 3, 135-140. http://dx.doi.org/10.4236/gsc.2013.34016

[9] Maikokera, R and Kwaambwa, H.M. (2007) Interfacial Properties and Fluorescence of a Coagulating Protein Extracted from Moringa oleifera Seeds and Its Interaction with Sodium Dodecylsulphate. Colloids and Surfaces B: Biointerfaces, 55, 173-178. http://dx.doi.org/10.1016/j.colsurfb.2006.11.029

[10] Ndabigengesere, A. and Narasiah, K.S. (1998) Use of Moringa oleifera Seeds as a Primary Coagulant in Wastewater Treatment. Environmental Technology, 19, 789-800. http://dx.doi.org/10.1080/09593331908616735

[11] Ndabigengesere, A. and Narasiah, K.S. (1998) Quality of Water Treated by Coagulation Using Moringa oleifera Seeds. Water Research, 32, 781-791. http://dx.doi.org/10.1016/S0043-1354(97)00295-9

[12] Kwaambwa, H.M. and Maikokera, R. (2008) Infrared and Circular Dichroism Spectroscopic Characterisation of Secondary Structure Components of a Water Treatment Coagulant Protein Extracted from Moringa oleifera Seeds. Colloids and Surfaces B: Biointerfaces, 64, 118-125. http://dx.doi.org/10.1016/j.colsurfb.2008.01.014 
[13] Fennell, D.E. and Wennerström, H. (1994) The Colloidal Domain: Where Physics, Chemistry, Biology, and Technology Meet. VCH Publishers, New York.

[14] Holmberg, K.K. (2001) Handbook of Applied Surface and Colloid Chemistry. John Wiley \& Sons Ltd., New York.

[15] Maikokera, R. and Kwaambwa, H.M. (2009) Use of Viscosity to Probe the Interaction of Anionic Surfactants with a Coagulant Protein from Moringa oleifera Seeds. Research Letters in Physical Chemistry, 2009, Article ID: 927329.

[16] Ndabigengerese, A., Narasiah, S.K. and Talbot, B.G. (1995) Active Agents and Mechanism of Coagulation of Turbid Waters Using Moringa oleifera. Water Research, 29, 703-710. http://dx.doi.org/10.1016/0043-1354(94)00161-Y

[17] Green, R.J., Su, T.J., Joy, H. and Lu, J.R. (2000) Interaction of Lysozyme and Sodium Dodecyl Sulphate at the AirLiquid Interface. Langmuir, 16, 5797-5805. http://dx.doi.org/10.1021/la000043t

[18] Kwaambwa, H.M. and Rennie, A.R. (2012) Interactions of Surfactants with a Water Treatment Protein from Moringa oleifera Seeds in Solution Studied by Zeta Potential and Light Scattering Measurements. Biopolymers, 97, $209-218$. http://dx.doi.org/10.1002/bip.22014

[19] Kwaambwa, H.M., Hellsing, M. and Rennie, A.R. (2010) Adsorption of a Water Treatment Protein from Moringa oleifera Seeds to a Silicon Oxide Surface Studied by Neutron Reflection. Langmuir, 26, 3902-3910. http://dx.doi.org/10.1021/la9031046

[20] Protein Calculator v3.3. http://www.scripps.edu/cgi-bin/cdputnam/protcalc.html

[21] Gassenschmidt, U., Jany, K.D., Bernhard, T. and Nierbergall, H. (1995) Isolation and Characterization of a Flocculating Protein from Moringa oleifera Lam. Biochimica et Biophysica Acta, 1243, 477-481. http://dx.doi.org/10.1016/0304-4165(94)00176-X

[22] Bröin, M., Santaella, C., Cuine, S., Kokou, K., Peltier, G. and Jöet, T. (2002) Flocculent Activity of a Recombinant Protein from Moringa oleifera Lam. Seeds. Applied Microbiology and Biotechnology, 60, 114-119. http://dx.doi.org/10.1007/s00253-002-1106-5

[23] Kwaambwa, H.M. and Maikokera, R. (2007) Air-Water Interface Interaction of Anionic, Cationic, and Non-Ionic Surfactants with a Coagulant Protein Extracted from Moringa oleifera Seeds Studied Using Surface Tension Probe. Water SA, 33, 583-588. 
Scientific Research Publishing (SCIRP) is one of the largest Open Access journal publishers. It is currently publishing more than 200 open access, online, peer-reviewed journals covering a wide range of academic disciplines. SCIRP serves the worldwide academic communities and contributes to the progress and application of science with its publication.

Other selected journals from SCIRP are listed as below. Submit your manuscript to us via either submit@scirp.org or Online Submission Portal.
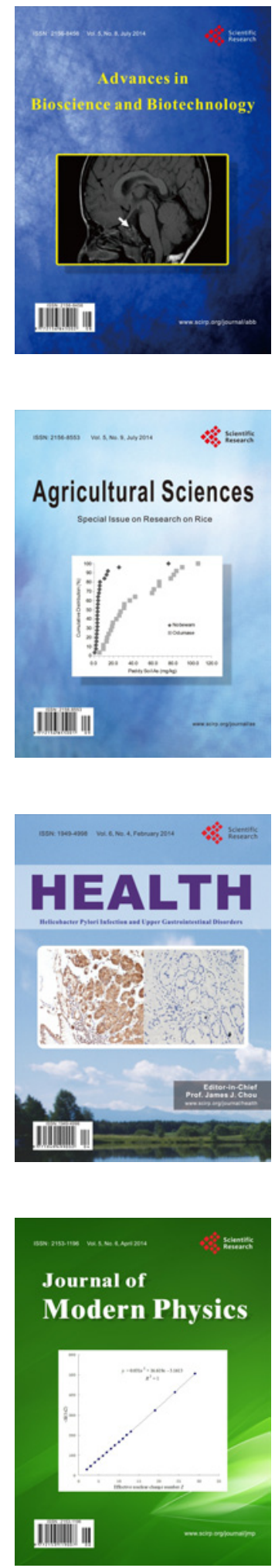
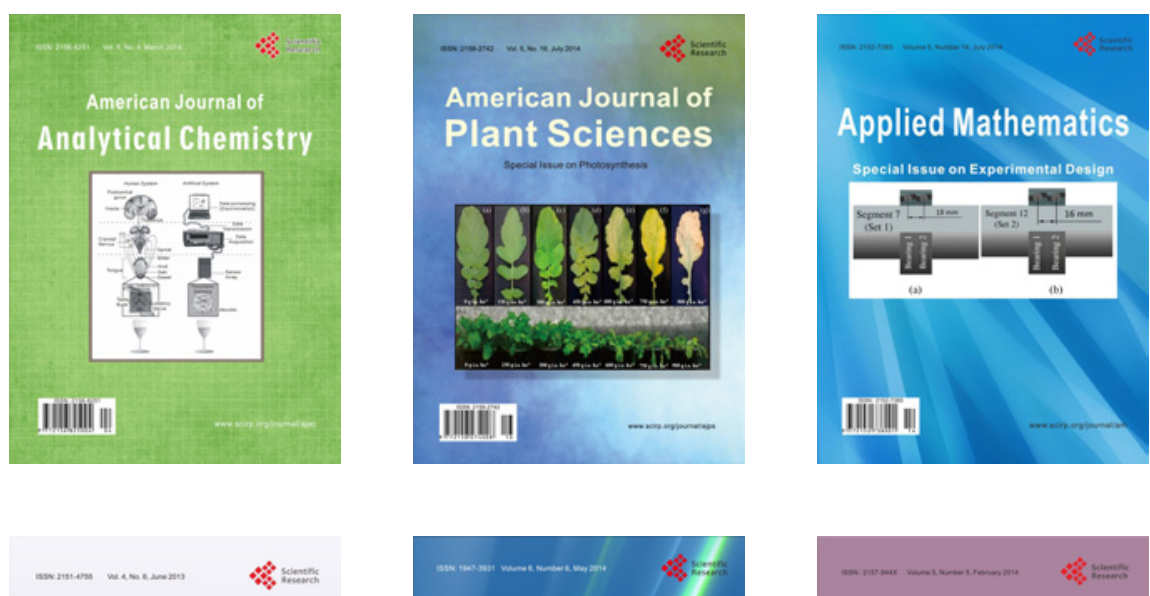

Creative Education
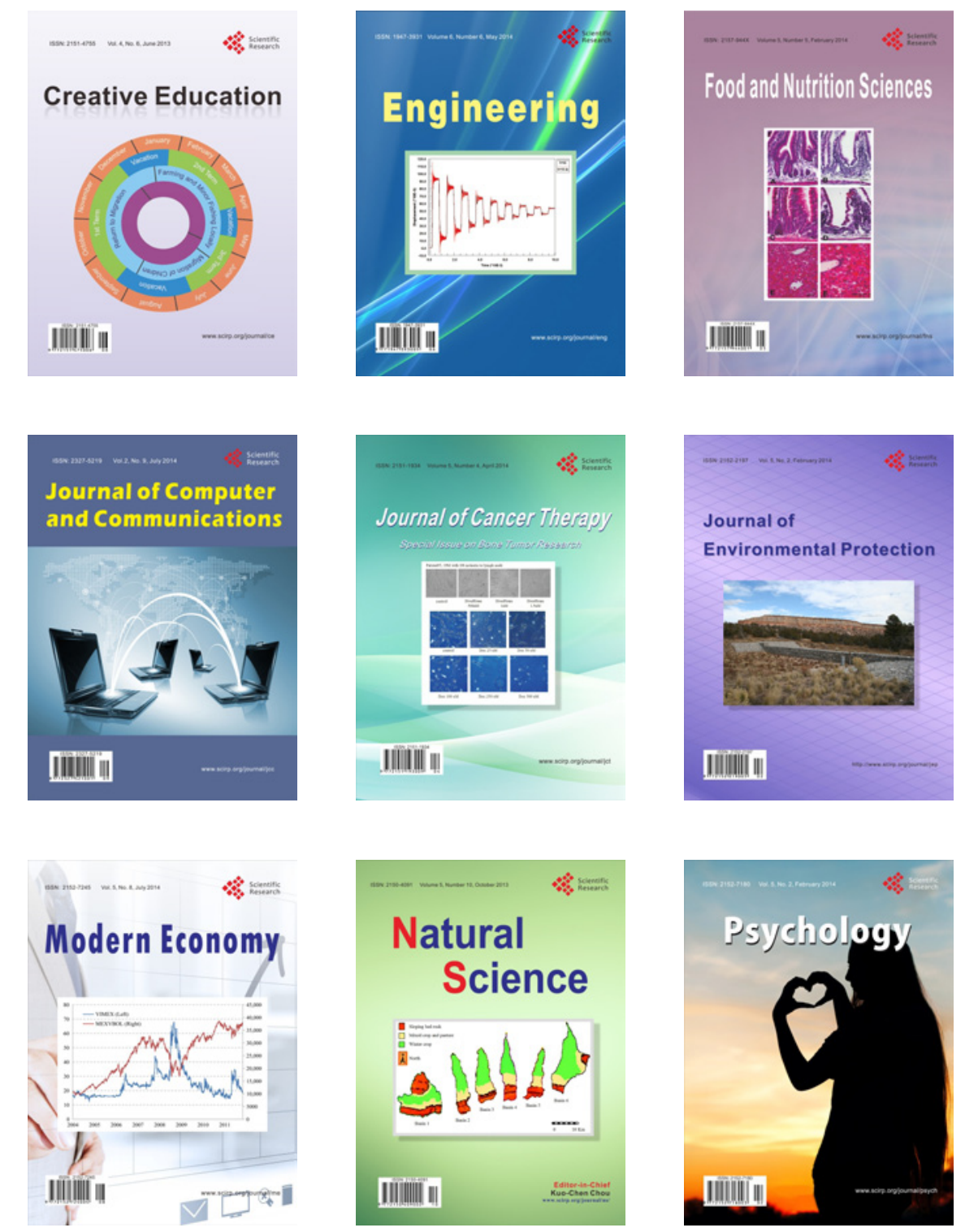